\title{
Impact and Challenges of Requirements Management in Enterprise Resource Planning (ERP) via ERP Thesaurus
}

\author{
Rahat Izhar ${ }^{1}$ \\ Research Associate/ ERP Consultant \\ Department of Software Engineering' \\ Bahria University Islamabad, Pakistan \\ Dr. Shahid Nazir Bhatti ${ }^{2}$ \\ Associate Professor \\ Department of Software Engineering \\ Bahria University Islamabad, Pakistan
}

\author{
Saba Izhar ${ }^{3}$ \\ Teaching Associate \\ Department of Management Sciences \\ Bahria University Islamabad, Pakistan \\ Dr. Amr Mohsen Jadi ${ }^{4}$
Associate Professor
Department of CCSE,
University of Hail, KSA
}

\begin{abstract}
Managing requirements efficiently aids the system design team to understand the existence and significance of any individual requirement, there are numerous requirements management practices that benefit in decision making but significantly many lacks to account the important factors that have substantial influence in managing requirements in context of ERP systems in particular. As highlighted comprehensively later in literature review section, requirements management failure is one of the pivotal aspects for the project(s) failure. The prime problem/lacking in software design and development is when it comes to requirements management the most vital thing that gets ignored is thinking before performing activities. As it should be the main step to save time, money and efforts. Further prominence other aspects in this are pivotal value about the software's running in industries, the question arises when their business need ERP system, and when requirements change or new requirements are emerged into the system, what are the obstacles faced and how these obstacles are accomplished. ERP systems are becoming the need of industries nowadays as various industries are facing problems regarding data loss; it is challenging for the owners to fetch all the information when they need it, accounting systems are slower and consuming a lot of time and many other issues likewise. This paper further illustrates in detail the important traits, issues toward businesses may have when ERP is implemented and when requirements are changed or not managed professionally what issues are faced by requirement engineering team and industries and thus how to resolve them.
\end{abstract}

Keywords-Enterprise Resource Planning (ERP); Product Owner (PO); requirements elicitation; requirements management; change management

\section{INTRODUCTION}

Requirement is something needed in order to meet an objective. Requirements management demonstrates that organization ensures and meets the needs of its all customers and stakeholders. Requirements Management has a great impact on communication between the team members and all the existing stakeholders as requirements modifications can be added at any stage of project therefore it's very vital for all the project team members and stakeholders to thoroughly adjust to the requirement changes where it's essential. Firstly business requirements are to be well-defined for ERP, business analysis play a pivotal role in requirements management as it is the responsibility of business analyst to get involved with the stakeholders to create a Requirement Management Plan (RMP) during the planning phase of the project that is ERP system for that specific organization. Requirement management plan includes roles and responsibilities of stakeholder's, requirements management process, requirements prioritization, requirements traceability, requirements change and control, requirement management tools, requirement versioning and many more. The business analyst goes about as an extension amongst business and IT, makes the business requirements that could be comprehended by the development engineers and also disclosing to the clients to the technical know-how of system in detail as required.

Customer relationship ought to be the most important factor while gathering business requirements, as requirements keep on changing throughout the overall requirement engineering process. One of the key factors for a business analyst is to make sure that requirements are properly visible and understood by all the stakeholders. The high level objective of a system under requirements gathering phase is achieved mainly by precision in business requirements. Lucid business requirements are thus obtained in a way that the end results of the project are crystal clear to the stakeholders [9]. A Business Requirements Document (BRD) must be maintained and iteratively checked by the business analyst because it summarizes the answers to the business questions what are the purely business problems that a customer's wants to get solve? For example, what job the customer wants to get accomplish? A business Analyst describes the constraints to a customer on any proposed solution from a business perspective. Thus BRD is formed for the effective communication between internal and external technology providers to provide with the 
appropriate solution that satisfies both the customer and business needs [9]. While gathering the business requirements the business analysts deliberates that all the requirements he have gathered are accurate and very relevant to business needs but when these business requirements are thoroughly analyzed these requirements come out to be inconsistent, incomplete and because of these inconsistencies (infect incomplete requirements) in business requirements the overall cost of a project increases [7]. The BRD document ensures the accuracy of business requirements from the business perspective for a customer [8]. When writing the BRD many things get repeated and although analysts take it as a problem but to that he would know that this is what they are expected to achieve in principle. Thus due to clear scope of BRD the clarity between the business objectives and the technical objectives are separated [9]. Business objective defines "what does the organization wants to be or what is the organization mission" whereas "the technical objective provides the ground where the business objectives are met".

\section{REQUIREMENTS MANAGEMENT}

Requirements Management describes the features that need to be completed, features include control and track of requirements and changes to requirements at any stage as the project is moved forward. Requirements management has an important portion in contributing better business results. Poor requirements management leads to greater failure chances of overall project [21]. The phases of requirements management process include requirements elicitation, requirements analysis, requirements documentation, requirements validation, change management and traceability as depicted in Fig. 1 below [22].

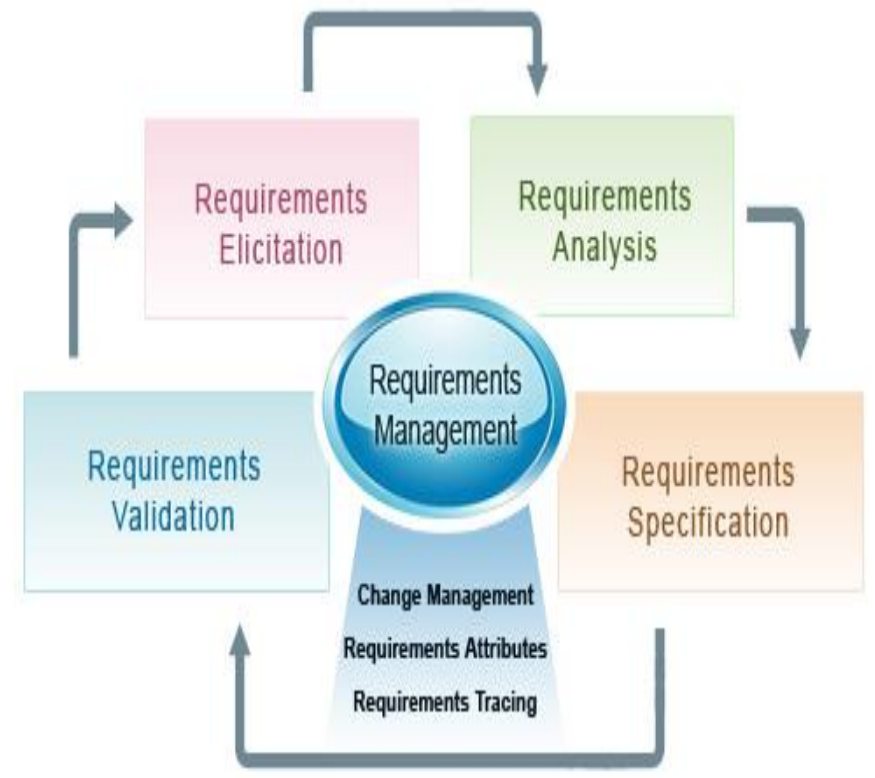

Fig. 1. Requirements Management Cycle [22].

Requirements Management process is iterative throughout the project. As Requirements Management is the continuous process throughout the project lifespan. As requirements are generated at any phase of the project by different stakeholders of the project for example customers could come up with new or some modifications in requirements, sales could come up with more new added requirements, management with their new or changed requirements, product management may add their more related requirements and so on [3]. There comes communication factor between all the stakeholders when new requirements or change in requirements are being managed. Project managers communicate all the new and existing factors with all the stakeholders. When it comes to communication between all stakeholders it's the responsibility of business analyst to get input from the project manager and create a requirements management plan.

A typical requirements management plan has following components in it [6] [11] [13] [14] [19]:

- Project overview: Brief description of project for the readers who haven't seen the project charter. It could be an overview copied from one's development agreement or any other summarized document.

- The requirements elicitation procedure: In this segment one will portray the procedure that one will use to evoke, investigate and record the necessities. Thus in this section one infect portraying the prerequisites procedure at a nitty gritty level. That is one might utilize various elicitation systems and there might be various distinctive procedures used [18].

- Roles and corresponding responsibilities: This segment records the roles that will be included with dealing the requirements through whatever remains of the task lifecycle. Roles could incorporate the task director, lead expert, customers, and so on. The task supervisor, for example, ought to have the general obligation regarding extension change management of the requirements. Somebody, maybe the lead expert, ought to have general duty regarding the respectability of the requirements all through whatever is left of the lifecycle [13].

- Tools: This includes the tools that are going to be used to accomplish the requirements. There are various technologies (tools) that can be utilized to record, oversee and track requirements through the lifecycle. The tools might be as straightforward as MS Word or Exceed expectations, or one may have more advanced requirements discovery, recording and programming tools in this [16] [18].

- Requirements traceability: The overall process of tracking/tracing requirements throughout the project lifecycle is described in this section. This procedure must then be supplemented to the agenda to guarantee the best possible following of requirements happens all through whatever is left of the project [21].

- Change Control: The formal process that is performed to manage the change in requirements is written in this section. It is expected that the formal scope change process is being implemented throughout the project. If this process is being used then it's applicable to the variations in requirements and if there's no official 
modification procedure is being used then a specific formal change process is documented in this section.

- Approval: The project manager's approves overall writings of the project and ensures the every document regarding requirements in this section.

Requirements management plan enables the whole project to be on the same page in regard to requirements elicitation and relevant requirements related issues. This could ensure an effective communication between the stakeholders and increasing number of odds of the projects success which comprises customer needs and achieving successful time-tomarket [3]. These advantages are particularly valid for substantial activities that include different, internationally disseminated utilitarian units.

\section{ERP SYSTEMS}

Enterprise Resource Planning (ERP) system helps the enterprise organizations to automate and integrate all their human resource management, financial management, material management, sales and distributions, production planning \& control, plant maintenance, document management and workflow, security and system administration activities [5], ERP makes business more profitable. The automation and integration of an organizations core business provides level of control [5]. That is business becomes smarter and strategic decisions are easy to make. It is like umbrella term for complicated type of software setup. It can be customized to entailer one's needs. Business needs specific software solution, as Fig. 2 shows some of the modules/ departments an ERP covers [4].

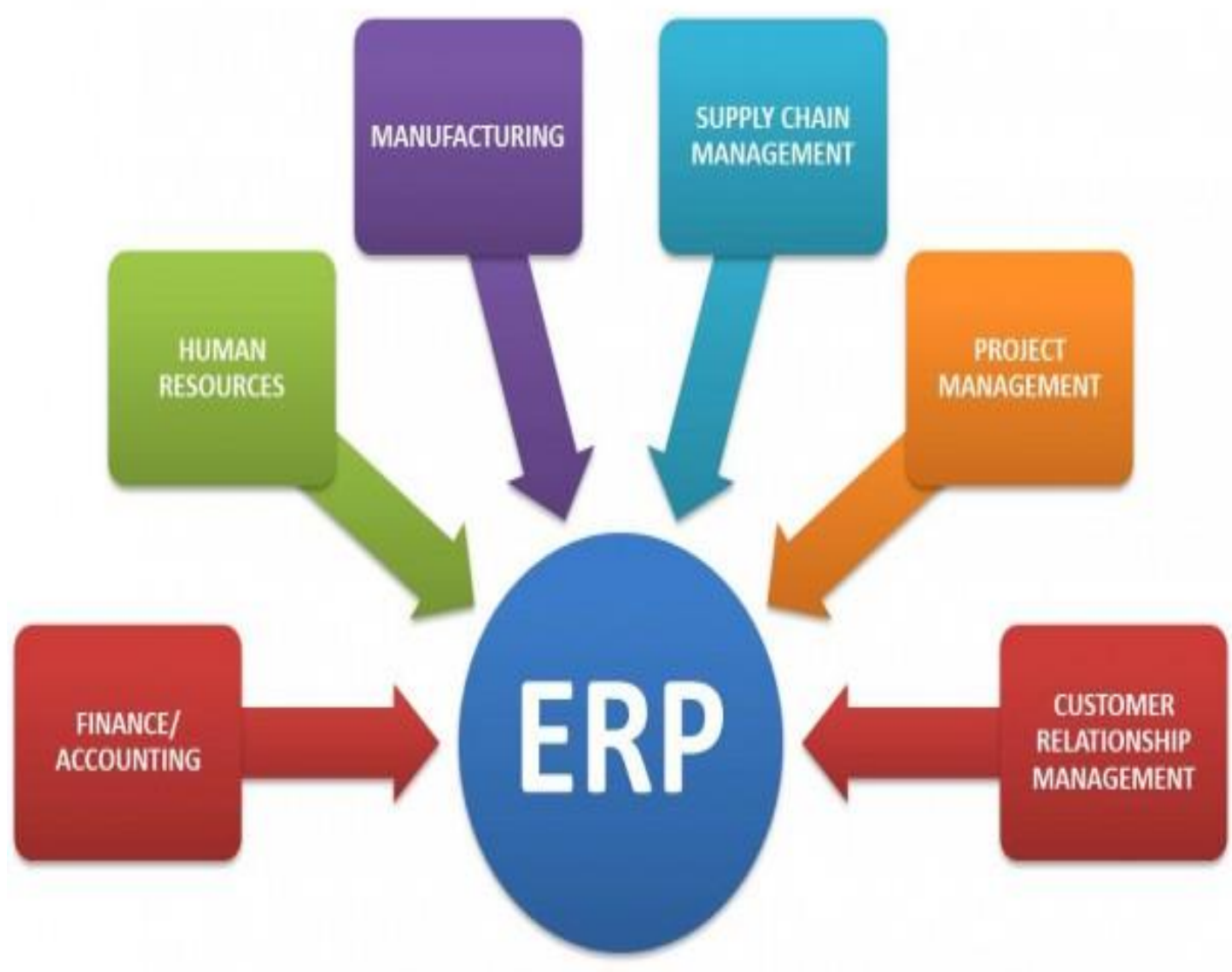

Fig. 2. Different Modules of ERP System [4] [11]. 


\section{ERP TECHNICAL DETAILS/ METHODOLOGY}

In ERP systems one have to have access to Task Management, Fleet Management, Human Resources, Notices, Expense Management, Purchase Management, Project Management, Invoicing, Stock Management, Dashboards, Detail Reports, 24/7 support and more other business modules. For example one stakeholder has a store this store bonds all his products. When product will be directed ERP will be included in every point of sequence. It will systematically schedule distribution and arrange to ship and deliver, thus observing in transit through convoy supervision and even replenish that product all inevitably. If there's something missed there is not a problem, it can be added or removed because ERP has a feature of customization [2]. ERP is advanced it can be controlled over the mobile phone at very affordable cost. Top five (5) signs one's business needs an ERP [3].

1) Different software's for different processes.

2) Difficult access to fetch information about one's business.

3) System gets slower i.e. accounting takes longer than it takes.

4) Sales and customer experiences are suffering.

5) The IT (automation) is too complex and time consuming.

Multiple components into one system: ERP optimizes the business, centralizes data, automatic handling, cost reduction, audit trails, business continuity and stability [3]. With ERP single stream of data is possible. Integrates and automates the data management and company's business processes.

ERP promises Accurate data, faster decisions making, lower operations costs. ERP is the tool of managing information which means, A company has its CRM (Customer Relationship Management) something manages all company's orders or warehouse. An accounting system and something filling the gap's in one's information pipeline which could be spreadsheet and manual procedures but none of these negotiation to each other, they do not part any information which impacts proficiency [8]. Efficiency is associated to time and money. At this stage ERP helps one the most as it centralizes all the information in one's organization, by enabling this one can stream line the course of data. As most of our business processes become connected End to End. All additional things become informal that is, single opinion of one's client so one can deliver better provision. Thus our team effort more proficiently as they have the evidences they needed and when one need to analyze that information since it's all in same place, one can report on it any way one want to do so [16].

\section{METHODS AND MATERIALS}

A. Critical Achievement Aspects Enterprise Resource Planning (ERP) System Implementation: An Investigative Study in Oman
[1], this research paper addresses to Critical Success Factors that are raised in Enterprise Resource Planning (ERP) System Application. These are main 10 basic CSF's can help organizations to accomplish fruitful usage of ERP framework. These CSF's are Clear Goals and Objectives, Strategic IT Planning, Monitoring and Evaluation of Performance, User Training and Education, Top Management Support, Vendor Support, Teamwork and Composition, User Involvement, Project Champion and Education on new Business Processes. The authors focuses that focusing in mind the primary objective is to encourage the tenacious achievement of ERP framework and to assurance a greater effect on the business performance; CSFs must be required with the ERP context amid the practice of ERP outline to commercial requirements. From this work, it can be easily determined that ERP framework drives basically three primary execution phases of framework life cycle and that includes pre-usage arrange, implementation stage, and post execution organize.

\section{B. A Commercial Procedure Modeling - Enable requirements Engineering Framework for ERP Implementation}

In [2], the authors describe that productive implementation of an ERP framework strongly relies upon the precise meaning of primary functional requirements. The following paper also discusses a case study that portrays and dissects the advantages of the use of a prerequisites designing system to help Enterprise Resource Planning (ERP) advancement. This system further consolidates the innovation driven and the procedure driven methodologies for prerequisites investigation and execution. Particular business process displaying strategies improve the system and help the detailing of the utilitarian determinations of the ERP framework and the administration of prerequisites.

The connected structure associates necessities designing with the ERP improvement life cycle and utilizes a business procedure demonstrating approach keeping in mind the end goal to help both the RFI and RFP creation. The approach shelters the hierarchical view, the procedural view and the data innovation see all together to characterize data innovation resolves related with the operation of the organization and the requirements of its partners. The proposed arrangement of exercises in manual, IT-empowered and robotized grants the simple disconnection of those that prompt useful determinations and empowers the age of more explanatory depictions in light of the accessible procedure streams.

The procedure displaying approach ensures that necessities definition isn't a self-assertive organization of various partners' conclusions however a cognizant and facilitated choice serving the key targets of the enterprise and its vision of its future procedures. Also, it bolsters it to characterize the level of selection of its procedures to ERP usefulness before the RFP procedure, guaranteeing that it will work as per its interesting business forms after the ERP usage. The making of the structure with the above attributes fulfils the principal inquire about goal. 


\section{The Design of Manufacture Components of ERP System based on Requirements Engineering of Electrical Manufacturing Services}

[3], this research paper describes that to lead the elicitation procedure successfully, the organization's partner ought to have a similar comprehension and information on the center term. In the examination and transaction of useful prerequisites, there has been a concentrated exchange between the designer and client on clarifying the hole between as-is and the to-be show. This progression is additionally a tedious advance after the elicitation step. This progression will be quicker if the organization has utilized the data framework in supporting the business procedure. With the involvement in utilizing the data framework application, the clients will see progressively the rationale of the framework in supporting the business procedure.

The author specifically addresses the Production Department in PT.TDK (one of the Electronic Manufacturing Service Companies located in Serang City Indonesia) has never utilized the data framework application previously; to date the business procedure is just upheld by spreadsheet. A business work in the generation territory that we have broken down is the gathering procedure. PT. TDK is an Electronic Manufacturing Service organization whose center business is to process get together of merchandise so there is no generation procedure from crude materials. Best practice as capacities required in outlining ERP frameworks in this investigation construct in light of business process on the PT. TDK. The capacities are coordinated isn't just ERP best practice; however there are particular capacities identified with government controls. Best practices in this investigation can be connected to alternate EMS organizations by considering the particular capacities.

\section{Modules and Investigation Scheme of Enterprise Resource \\ Planning Requirements in Small and Medium Enterprises}

In research work [4], authors describes that an ERP requirements investigation scheme for ERP system development in directive to yield the appropriate ERP system utilities for small and medium enterprises by cutting down the parts of necessities and the association of the commercial procedure demonstrating, a few fundamental ideas are given and the technique for the procedures analysis and modelling is additionally communicated. The method used for the ERP requirements matching the SME's requirements is systematic. By providing approaches a) the post perceptible link within functionality and ERP requirements b) an international go through of ERP system working.

\section{E. Formalizing Requirements in ERP Software Implementations}

In [5], authors address to the research problem of functional and data challenges in ERP. They point out two systems by applying bipartite graphs and determine the matching functionalities through analysis. In spite of the fact that execution scope develops exponentially, putting the greater part of the spaces required into one single bi-chart definition was most certainly not conceivable; authors apply a gathering of sub-charts.
A bipartite diagram $\mathrm{G}$ can be considered as an item $\mathrm{G} \sim=\mathrm{H}$ $\times \mathrm{K} 2$ of a chart $\mathrm{H}$ with the relating finish chart $\mathrm{K} 2$ like considering a significantly number $\mathrm{g}$ into an item $\mathrm{g}=\mathrm{h} \times 2$, with the exception of that for charts the factorization require not be one of a kind. This exchange off was convenient in running iterative improvement forms. Finally they describe in a case study the event bidding process, analysis of legacy systems and agile product line implementation and provide the results into one signal bi-chart.

\section{F. Enterprise Resource Planning Classifications: \\ Requirements Analysis, Assessment and System Choice- ERP Decision Analysis Using a Game Theory Approach}

In [6], authors propose some of those amusements and explore the effect of specific practices in the ERP prerequisites examination process, ERP assessment process and with ERP framework decision, situated with regards to two genuine cases. They describe three organizations that have done prerequisites examination, assessed and picked between various ERP frameworks. Those cases are utilized to delineate different potential recreations that can be played. Also abridges a few prerequisites investigation programming and qualities of that product, for example, a solitary component can "execute the arrangement." Plus describe ERP requirements examination and coming about amusement playing practices, for example, influencing utilization of "bargain slaughtering" requirements or modifying their needs on requirements with a specific end goal to impact to framework decision. As they examine how firms assess diverse ERP frameworks and a portion of the amusement playing practices that can come about, for example, changing branch assessment weights to impact the framework decision. In this way, few issues can happen in framework decision through plan setting in various branches, altogether impact framework decision. And ends up by Stacking the Deck" that is picking individuals from the assessment group to finds the solution that was to be investigated.

\section{G. ERP Requirements for Supporting Management Decisions and Business Intelligence}

In research work [7], the author presents a hypothesis test for finding the essentialness of directors needs in the field of choice help and Business Intelligence, 11 things were separated as noteworthy needs. The discoveries of the exploration are the contrast between the measures of utilizing mechanized data frameworks during the time spent basic leadership among various levels of administrators. The discoveries demonstrated the profound contrast in the necessities of choice bolster among various levels of administrators. The analysis describes that if tools for reacting to choice help and BI needs are actualized in ERP frameworks, they ought to be tweaked deliberately as to the level of administration that utilizations them and their profundity and points of interest ought to be set by the methodologies of various administrators towards computerized frameworks. With a specific end goal to react to the reported needs, different devices and BI arrangements were likewise prescribed.

To organize the usage of these arrangements in ERP frameworks, the weights of criteria (requirements and necessities) and need for executing the choices (BI arrangements) were computed from an official viewpoint in 
light of requirements as criteria of basic leadership and in light of anthropic skills and intuitive improvement strategy .The outcome can be a suitable guide for providers of these frameworks and associations that expect to actualize them.

\section{H. Improving ERP Requirements Specification Process of SME's with a Customer-Centered Analysis Method}

In [8], the authors initially highlight the qualities of Small Medium Enterprises (SMEs') ERP ventures and through contextual investigations examine how they could be developed all the more viably. They describe that propose propelled strategy for SMEs' ERP prerequisite detail that incorporates operational, relevant and hazard examination. Together these investigations give an entire top to bottom depiction of organization business process advancement, determine the prerequisites for the new ERP framework, and recognize the confinements and dangers identified with the ERP venture.
The consequences of a contextual analysis in which the strategy has been connected, bolster advance improvement towards an all-encompassing and multidisciplinary approach in the ERP necessities particular procedure of SMEs. Further they proposed a new vendor and software independent method for ERP requirement specification of Small Medium Enterprises. The proposed technique has clear focal points since organization particular prerequisites are considered and is applied in different SME's to discover its appropriateness for the organization and its business.

\section{REQUIREMENTS MANAGEMENT IN ERP}

A comprehensive and systematic analysis of the research work accomplished in context of 'Requirements Management in ERP' by the different researchers, practitioner is highlighted in detail in Table I below.

TABLE I. COMPREHENSIVE ANALYSIS OF CONTRIBUTIONS AND LIMITATIONS OF REQUIREMENTS MANAGEMENT WITH RESPECT TO ERP VIA LITERATURE

\begin{tabular}{|c|c|c|c|}
\hline Author & Year & Overall Contribution & Limitations \\
\hline $\begin{array}{l}\text { Nikolaos A. Panayiotou, Sotiris } \\
\text { P. Gayialis, } \\
\text { Nikolaos P. Evangelopoulos [2] }\end{array}$ & 2014 & $\begin{array}{l}\text { Presentation of ERP reference models } \\
\text { gathered with organization processes can } \\
\text { lead to successful implementation of ERP } \\
\text { system. }\end{array}$ & $\begin{array}{l}\text { Single case study provided in a representative manufacturing } \\
\text { company, but further research in other industries can be conducted } \\
\text { to find out other requirements and success factors for implementing } \\
\text { ERP system. }\end{array}$ \\
\hline $\begin{array}{l}\text { Kursehi Falgenti, Chandra Mai, } \\
\text { Said Mirza Pahlevi [3] }\end{array}$ & 2015 & $\begin{array}{l}\text { Presentation of ERP reference models } \\
\text { gathered with organization processes can } \\
\text { lead to successful implementation of ERP } \\
\text { system. }\end{array}$ & $\begin{array}{l}\text { Single case study provided in a representative manufacturing } \\
\text { company, but further research in other industries can be conducted } \\
\text { to find out other requirements and success factors for implementing } \\
\text { ERP system. }\end{array}$ \\
\hline $\begin{array}{l}\text { Yousef Khaleel, Anmar } \\
\text { Abuhamdah, Mutaz Abu Sara, } \\
\text { Bassam Al-Tamimi [21] }\end{array}$ & 2015 & $\begin{array}{l}\text { Proposed conceptual components of ERP } \\
\text { requirements required for initiating ERP } \\
\text { system functions. }\end{array}$ & ERP system required only for small medium enterprises. \\
\hline $\begin{array}{l}\text { Talukdar S. Asgar and Tariq M. } \\
\text { King [5] }\end{array}$ & 2016 & $\begin{array}{l}\text { Proposed an approach that uses bipartite } \\
\text { graphs to formalize ERP requirements using } \\
\text { a case study author also describes how this } \\
\text { model can be used to formalize large scale } \\
\text { projects that are an ERP implementation. }\end{array}$ & $\begin{array}{l}\text { Beneficial for many ERP software engineering process. All } \\
\text { domains in a Single graph was impossible so multiple bi-graphs that } \\
\text { is sub graphs are used. Future work involved development of a tool } \\
\text { that may be able to define multiple domains. }\end{array}$ \\
\hline Daniel E. O’Leary [7] & 2000 & $\begin{array}{l}\text { Reviewed some games and compared with } \\
\text { the impact of certain ERP requirement } \\
\text { analysis and requirement evaluation process } \\
\text { in ERP systems. }\end{array}$ & $\begin{array}{l}\text { Focus was only on two branches that is two requirements at a time. } \\
\text { But the analyses can be extended to more requirements at a time. }\end{array}$ \\
\hline $\begin{array}{l}\text { Mehdi Ghazanfari1, Mostafa } \\
\text { Jafari and M. T Taghavifard } \\
\text { [8] }\end{array}$ & 2009 & $\begin{array}{l}\text { Survey of fundamental expectations of } \\
\text { managers for various levels of ERP systems } \\
\text { and provided the significance of } \\
\text { requirements for business intelligence for } \\
\text { ERP systems proposed using statistical } \\
\text { analysis tool. }\end{array}$ & $\begin{array}{l}\text { Focused on the tools for decision support and BI needs in an ERP } \\
\text { system that must be customized precisely }\end{array}$ \\
\hline Inka Vilpola1; Ilkka Kouri [9] & 2005 & $\begin{array}{l}\text { Provided the characteristics and case study } \\
\text { how SME's ERP projects can be evolved } \\
\text { more successfully. Methods for SME's ERP } \\
\text { requirement specification that has } \\
\text { operational, contextual and risk analysis. }\end{array}$ & $\begin{array}{l}\text { Specifically focused on characteristics and provided methods for } \\
\text { only small medium enterprise ERP systems. }\end{array}$ \\
\hline
\end{tabular}




\begin{tabular}{|l|l|l|l|}
\hline $\begin{array}{l}\text { Ali Tarhini1, Hussain Ammar1, } \\
\text { Takwa Tarhini \& Ra'ed } \\
\text { Masa'deh [10] }\end{array}$ & 2015 & $\begin{array}{l}\text { Provided a systematic review of 35 research } \\
\text { articles published on critical success factors } \\
\text { of ERP system implementation between 2000 } \\
\text { and 2013. 51 CSF's in ERP implementation } \\
\text { are suggested important. }\end{array}$ & $\begin{array}{l}\text { Reviewed research papers only and provided several CSF's for } \\
\text { more efficient and successful ERP systems. }\end{array}$ \\
\hline $\begin{array}{l}\text { Jan Mittner, Alena Buchalcevova } \\
\text { [11] }\end{array}$ & 2014 & $\begin{array}{l}\text { Surveyed that small companies are not } \\
\text { satisfied with software systems. Based on } \\
\text { literature analysis, market and own } \\
\text { experience first version of requirement } \\
\text { specification of ERP system for small } \\
\text { companies was created and validated. }\end{array}$ & Focused specifically on small companies' requirements. \\
\hline $\begin{array}{l}\text { Jun Li a, Tangtang Xie b and } \\
\text { Shuang Du [12] }\end{array}$ & 2011 & $\begin{array}{l}\text { Proposed five functions that an ERP system } \\
\text { must have for small and medium publishers } \\
\text { for increasing the flexibility and efficiently } \\
\text { solving many problems like business } \\
\text { problems. }\end{array}$ & $\begin{array}{l}\text { Limited to only small and medium publishers to increase the } \\
\text { efficiency and flexibility of ERP system modules. }\end{array}$ \\
\hline $\begin{array}{l}\text { Ahmad Saleh Shatat [10] and } \\
\text { [20] }\end{array}$ & 2015 & $\begin{array}{l}\text { Important role of critical success factors } \\
\text { CSF's in ERP system. }\end{array}$ & $\begin{array}{l}\text { Limited to only Critical success factors in ERP and specially study } \\
\text { was investigated in only Oman. }\end{array}$ \\
\hline
\end{tabular}

\section{VII.ERP BUSINESS FACTORS}

Early Researches [3] [9], [10] published research work on ERP business factors may include the following critical success factors (CSF's):

- Top Management support and inclusion

- Project Competence and association

- Clear objectives destinations and extension

- User preparing and training

- Change Management

- Business process Reengineering

- Effective communication

- User association

- Data examination and transformation

- Consultant

- Architecture choice

- Minimal customization

- Project Management

Implementing an ERP system in an organization is a very crucial process. Requirement engineering team must know the overall details and relevant factors of the system intensively. Various components must be considered and requirements must be gathered before implementation of the ERP system [8]. Requirement engineering team must go through all the departments in an organization and then decide which component must be implemented. Critical success factors must be considered perfectly so that a successful ERP could be implemented.

Different organizations have different requirements and according to the thorough analysis of those requirements ERP system takes place [8]. Fig. 3 shows some common modules an ERP have for medium and small organizations.
When an ERP is implemented it must fit well with the company's present operations and structures and it ought to in like manner have the limit to convey on key execution and gainfulness objectives that the company's current frameworks cannot convey [10]. This is a troublesome demand as it is furthermore the inspiration driving why ERP has a higher failure rate. It can be a calling completing endeavor for a few of the directors if an ERP foundation doesn't go well. Thus it is the responsibility of requirements engineering team to get involved with the organization so that a successful ERP can be implemented in place.
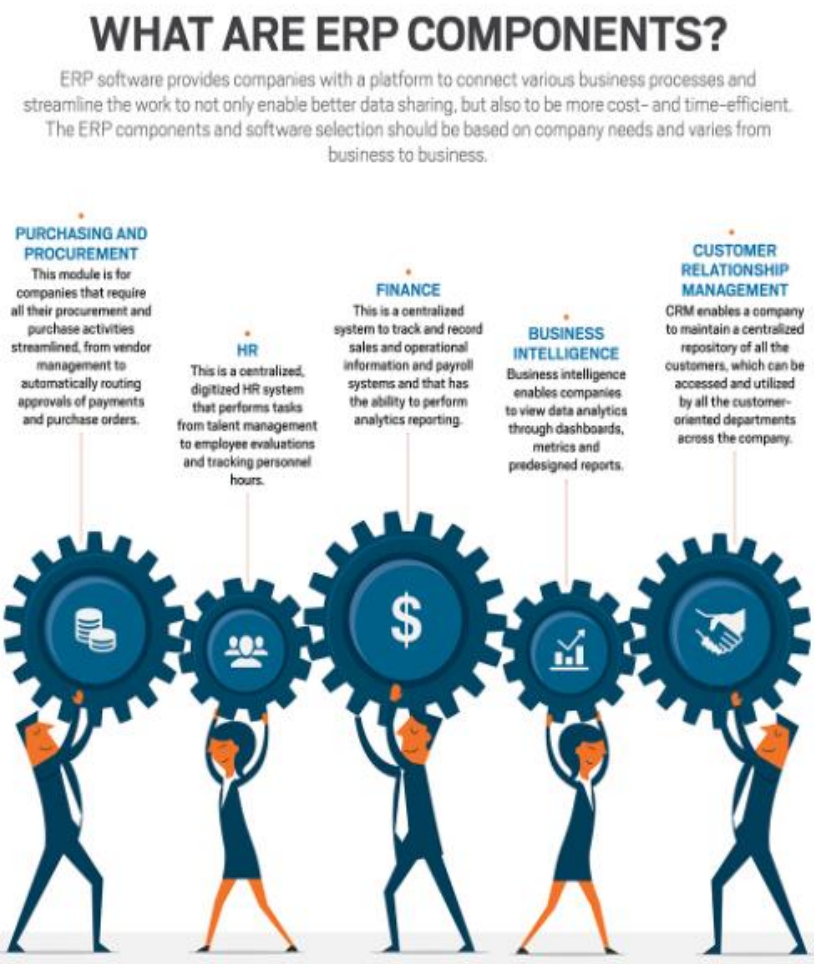

Fig. 3. Components of ERP [4] [10]. 


\section{EFFECT OF CHANGE MANAGEMENT TO ERP}

When an ERP system is getting in to place in an organization it is very difficult for the staff to grasp the whole system easily at the start. Many of the staff members do not agree with changing the environment because they were comfortable with the old system and start feeling about the new system as a burden. It is the responsibility of the high authority (management) to provide trainings to the staff of new system and explaining the reason why the old system is discarded and how the new system will benefit them. The organizations that are already having ERP system in place and are not satisfied with that ERP system it is difficult to implement in such organizations because it takes a huge amount of time to analyze their system and implementing new system accordingly. Whereas those organizations that are not having any ERP system and doing work on excel sheets and using different software's for different processes it is much easier to place an ERP system in such organizations because modules can be directly implemented and get integrated with other departments. Fig. 4 illustrate a snapshot of requirement elicitation regarding an ERP system that is how requirements elicitation is used in ERP system's to confirm the requirements of stake holders and requirement engineers.

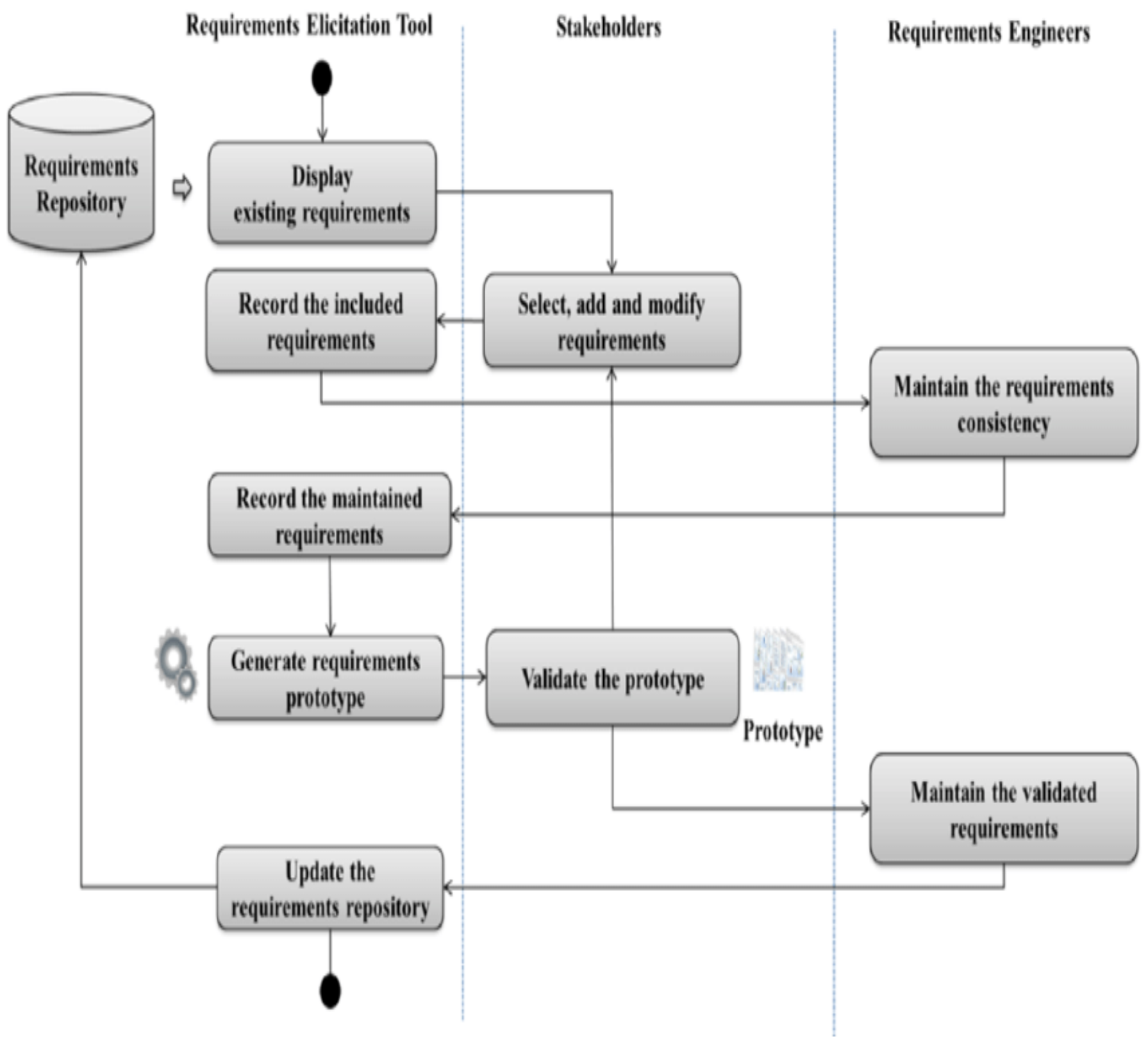

Fig. 4. Requirements Elicitation in ERP System [20]. 


\section{ERP CHECKLIST}

The prime idea is that whenever an enterprise organization requires a system that is integrated and fulfilling business needs properly, requirement engineering teams plays a vital role while a new system is being built for an organization. For example ERP covers all the departments in an enterprise organization that is it cover the entire financial accounting module, human resource management module, manufacturing and distribution module, material management module, sales and inventory module, supply chain module, customer Relationship module, integration capabilities, and support. Further these modules are elaborated and checklist for each module is shown in figures below [15] [17] [19].

\section{A. Financial Accounting Module}

Financial module must cover's all the functionalities that are related to financial activities. The task of requirement engineer's here should be to make a proper checklist for the stakeholders to let them know about what each module essential factors may have to be there. Fast analysis and proper accuracy makes fewer amount of errors and allows the organizations to have proper knowledge of its financial health. The vital thing to consider on the grounds that ERP computerizes a few departments in finance accounting, for example, finances, invoicing and planning, that more often than not take many staff hours on a month to month premise [4]. Fig. 5 shows a requirements checklist that must be checked by requirement engineer for a successful ERP financial accounting module.

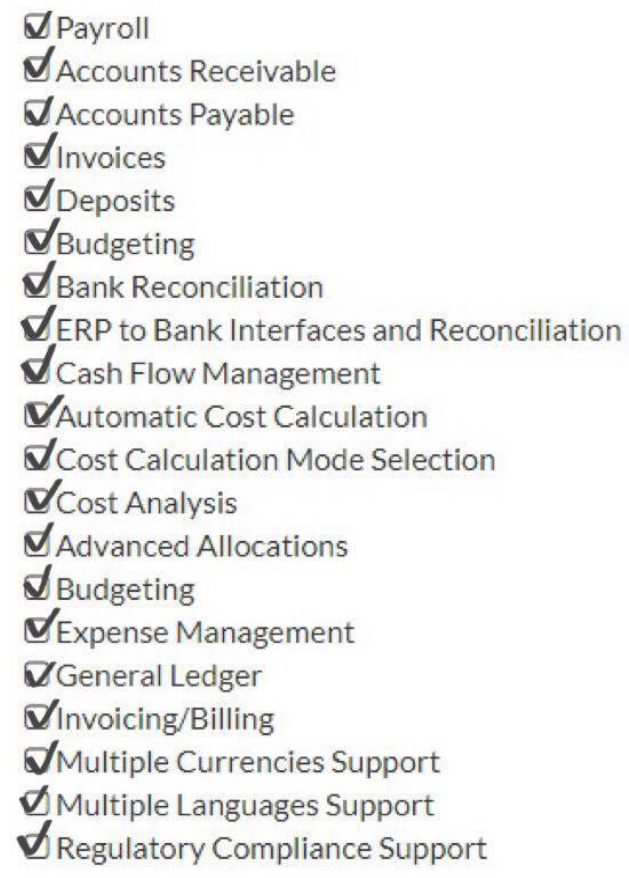

Fig. 5. Financial Accounting Checklist.

\section{B. Human Resource Management Module}

The automation of HRM module reduces the human errors like tax calculations and benefits the administration by monitoring all the individual productivity and managing hiring data. This will profit the organization increasing its efficiency and financial losses are reduced that were due to imprecision [7]. Fig. 6 shows a requirements checklist that must be checked by requirement engineer for a successful ERP HRM module and its relevant features.

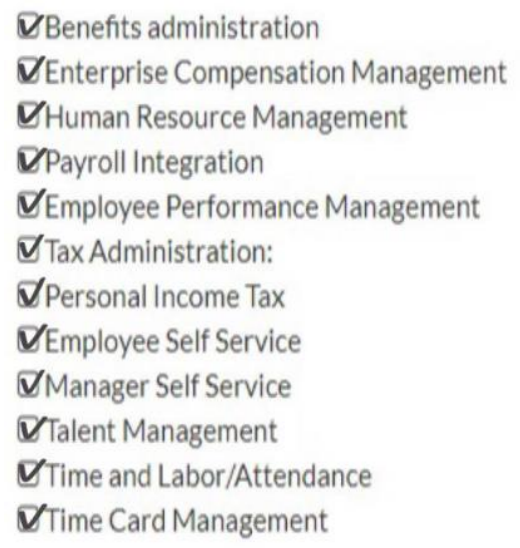

Fig. 6. HRM Checklist.

\section{Manufacturing and Distribution Module}

The signs of a successful ERP are that it must be able to manage manufacturing and distribution processes to spare time and cash by amplifying staff hours [15]. Manufacturing and distribution process is useful because it covers entire tasks of distribution scheduling, production control and quality analysis and saves the extra hours that the staff may consume without this module. Fig. 7 shows the checklist that must followed by requirement engineer for successful ERP manufacturing and distribution module.

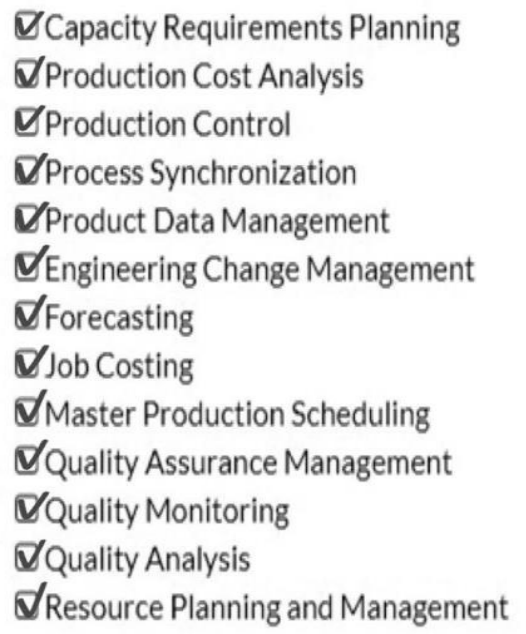

Fig. 7. Manufacturing and Distribution Checklist.

\section{Material Management Module}

All the business activities related to stock for example deliveries, monitoring and orders are covered in this module. Business Intelligence tools in ERP helps the organizations to predict sales trends to control stock level. The functionalities 
and features of this module help the retailers and manufacturers to maximize storage space, get rid of unproductive inventory and meet revenue goals [12]. Fig. 8 shows a requirements checklist that must be checked by requirement engineer for a successful ERP Material management module.

\section{DMRO \\ $\checkmark$ Availability of Materials \\ $\checkmark$ Availability of Stock \\ $\checkmark$ Optimum Store Inventory $\checkmark$ Planning}

Fig. 8. Material Management Checklist.

\section{E. Sales and Inventory Module}

This module covers all the sales and order management that is investigations sales information, computerizes exchanges, screens execution, tracks costs and even oversees arranges readiness and client credit. This will allow the real time location of any item available in the inventory. The Automatic price/profit calculation will help to save the time and effort and increase efficiency and accuracy of the business. Fig. 9 shows a requirements checklist that must be checked by requirement engineer for a successful ERP Sales and Inventory module.

\section{$\boldsymbol{\nabla}$ Customer Credit Management \\ $\checkmark$ Pricing \\ $\checkmark$ Picking \\ $\boldsymbol{\nabla}$ Quotations \\ $\boldsymbol{\nabla}$ Sales Order Processing \\ $\boldsymbol{\nabla}$ Capable to Promise Inventory \\ $\boldsymbol{\nabla}$ Bill of Materials \\ $\boldsymbol{\nabla}$ BOM Reporting \\ $\boldsymbol{\nabla}$ Credit Card Processing \\ УOnline Transaction Reporting \\ $\nabla$ Sales Order Management}

Fig. 9. Sales and Inventory Checklist.

\section{F. Supply Chain Module}

Managing various processes like procurement processes, material resource management, supply chain management, complex processes, distribution and delivery planning and reduces the risk of human error. This module of ERP is mainly beneficial for distributors, retailers and manufacturers. Fig. 10 shows a requirements checklist that must be checked by requirement engineer for a successful ERP supply chain module.

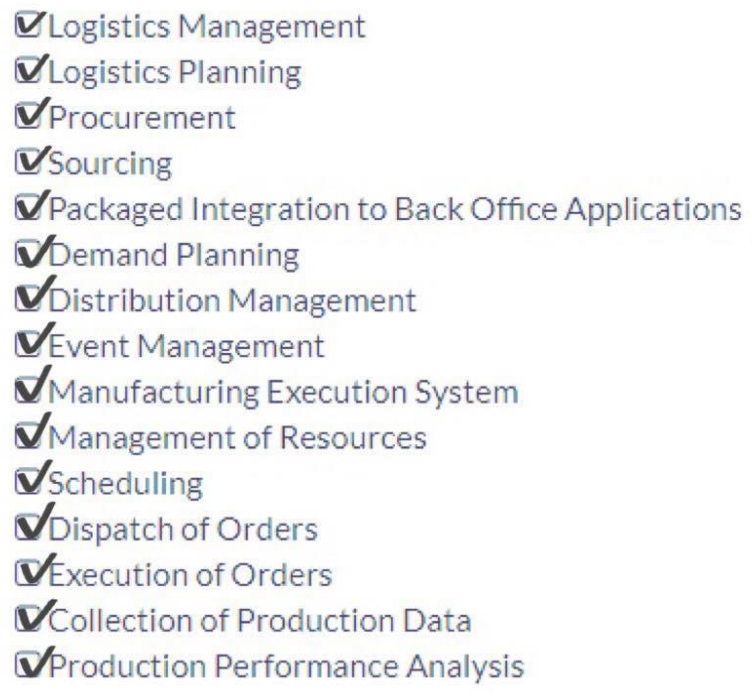

Fig. 10. Supply Chain Checklist.

\section{G. Customer Relationship Module}

As the customer satisfaction is the most important part of any business success. ERP must provide the Comprehensive customer tools in Organizations for accomplishment of customer satisfaction and robust sales. Fig. 11 shows a requirements checklist that must be checked by requirement engineer for a successful ERP customer relationship module.

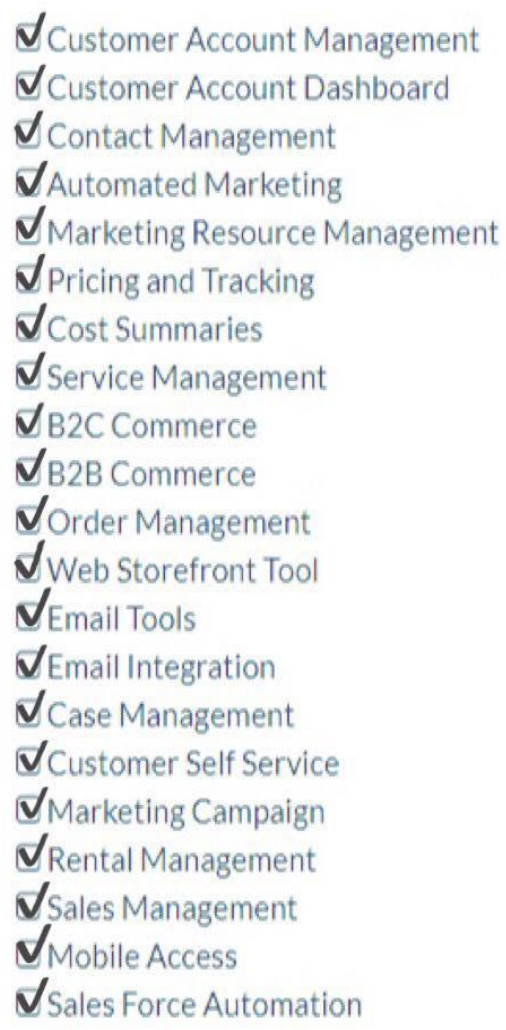

Fig. 11. Customer Relationship Checklist. 


\section{H. Integration Capabilities}

ERP integration ensures that the employees of the organization use the system quickly and effectively. Once ERP system is implemented it allows analyzing data, generating real time reporting, performing business tasks and integration of any new application is easy. Fig. 12 shows a checklist of integration capabilities of an ERP system.

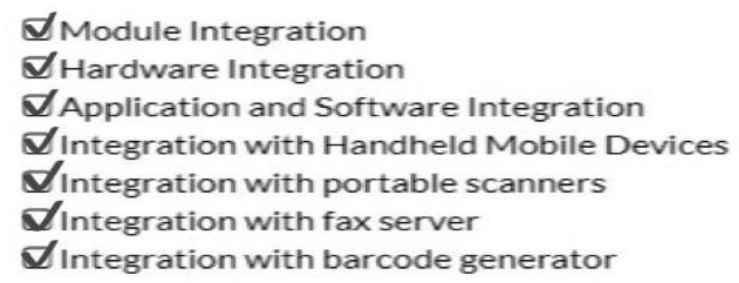

Fig. 12. Integration Capabilities Checklist.

\section{Support}

The most important thing for an ERP provider is that it ensures and supports the user support. As ERP system is a huge system it requires training, troubleshooting and repairs when implemented. Fig. 13 shows the support and ERP must provide after implementation.

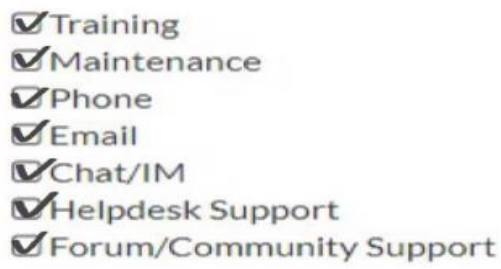

Fig. 13. Support Checklist.

These all modules corresponding checklists may help the ERP system requirements engineers and developers to make an effective system that is having all the functionalities and features included in each module and developing a successful ERP for an enterprise organization to meet the customers as well as business needs.

\section{CONCLUSION}

Requirements emerge throughout the software design and development processes and thus requirements are needed to manage with utmost significance, especially when the scenario is that of ERP Systems. As disused and emphasized in this work, there are various requirements management practices, methodologies proposed and been trailed but most of them fail to justify those classical factors (metrics) [21] that influence the overall design and implementation of software product (attributes) being developed. The pivotal idea thus here is that the system requirements must be gathered completely by requirements engineering team before designing and developing a system. ERP system(s) are becoming prominent/ in need in this era for enterprise organizations. An organization must be thoroughly analyzed that is the requirements engineering team must create all the related documents and complete work to develop a successful system for the concerned organization. All the functionalities and features (as highlighted in section IV of this paper) of the modules discussed above must be gone properly to ensure that the ERP system is complete and consistent for that particular organization.

\section{REFERENCES}

[1] Ramayah, T., Arokiasamy, S., \& Eri, Y. (2005). Critical Success Factors in Enterprise Resource Planning (ERP) system Implementation: Results from an Exploratory Study. 2nd International Conference on Business \& Economics, "Capitalising the Potential of the Asian Integrated Market, 28(1), 2005.

[2] Panayiotou, N. A., Gayialis, S. P., Evangelopoulos, N. P., \& Katimertzoglou, P. K. (2015). A business process modeling-enabled requirements engineering framework for ERP implementation. Business Process Management Journal, 21(3), 628-664. http://doi.org/10.1108/BPMJ-06-2014-0051

[3] Falgenti, K., Mai, C., \& Pahlevi, S. M. (2016). The design of production modules of ERP systems based on requirements engineering for Electronic Manufacturing Services company. 2015 International Conference on Information Technology Systems and Innovation, ICITSI 2015 - Proceedings, (March 2016). http://doi.org/10.1109/ICITSI.2015.7437709

[4] Khaleel, Y., Abuhamdah, A., Sara, M. A., \& Al-Tamimi, B. (2016). Components and analysis method of enterprise resource planning requirements in small and medium enterprises. International Journal of Electrical and Computer Engineering, 6(2), 682-689. http://doi.org/10.11591/ijece.v6i2.8372

[5] Asgar, T. S., \& King, T. M. (2016). Formalizing Requirements in ERP Software Implementations. Lecture Notes on Software Engineering, 4(1), 1-40. http://doi.org/10.7763/LNSE.2016.V4.220

[6] Sehrish Alam, Dr. Shahid Nazir Bhatti, Impact and Challenges of Requirement Engineering in Agile Methodologies: A Systematic Review, International Journal of Advanced Computer Science and $\begin{array}{lll}\text { Applications } & \text { (IJACSA), } & 817 \text { (4), }\end{array}$ http://dx.doi.org/10.14569/IJACSA.2017.080455

[7] O'Leary, D. (2000). Game Playing Behavior in Requirements Analysis, Evaluation, and System Choice for Enterprise Resource Planning Systems. Icis, (May), 385-395 Paper 35.

[8] Ghazanfari, M., Rouhani, S., \& Jafari, M. (2009). ERP Requirements for Supporting Management Decisions and Business Intelligence. The IUP Journal of Information Technology, V(3), 65-84.

[9] Vilpola, I., \& Kouri, I. (2005). Improving ERP Requirement Specification Process of SMEs with a Customer-Centered Analysis Method. Frontiers of E-Business Research 2005, (October), 140-151.

[10] Tarhini, A., Ammar, H., Tarhini, T., \& Masa'deh, R. (2015). Analysis of the Critical Success Factors for Enterprise Resource Planning Implementation from Stakeholders' Perspective: A Systematic Review. International Business Research, 8(4), 25-40. https://doi.org/10.5539/ibr.v8n4p25

[11] Mittner, J., \& Buchalcevova, A. (2014). The ERP System for an Effective Management of a Small Software Company - Requirements Analysis. Journal Of Systems Integration, 5(1), 76-87. https://doi.org/10.20470/jsi.v5il.187

[12] Li, J., Xie, T., \& Du, S. (2011). Requirements analysis on flexibility of ERP system of medium and small publishers. Procedia Engineering, 15, 5493-5497. https://doi.org/10.1016/j.proeng.2011.08.1019

[13] Rashid, A., Zekeriya-Nas, Shami, M. U. D., Muhmood, U., Naila-Gul, \& Ceylan-Oklu. (2009). Windmills \& CSFs for ERP-diffusion of technovation in academia-industry: A qualitative analysis. PICMET: Portland International Center for Management of Engineering and Technology, Proceedings, (September), 2711-2721. https://doi.org/10.1109/PICMET.2009.5261794

[14] Felderer, M. (2014). Novel Methods and Technologies for Enterprise Information Systems, 8(January 2016). https://doi.org/10.1007/978-3319-07055-1

[15] Sudzina, F., \& Johansson, B. (2007). Finding ERP requirements that support strategic management in organizations, (December). 
[16] Yang, H. (2016). Project Team Right-sizing for the Successful ERP Implementation. Procedia Computer Science, 91(Itqm), 672-676. https://doi.org/10.1016/j.procs.2016.07.168

[17] Johansson, B., \& de Carvalho, R. A. (2010). Software tools for requirements management in an ERP system context. Proceedings of the 2010 ACM Symposium on Applied Computing - SAC '10, (January), 169. https://doi.org/10.1145/1774088.1774123

[18] Goud Sandhil, S., \& Vishal Gupta, N. (2013). Enterprise Resource Planning (ERP) - A tool for uninterrupted supply in pharmaceutical supply chain management. International Journal of Pharmacy and Pharmaceutical Sciences, 5(3), 103-106.

[19] Zamiri, A., Rostampour, A., \& Nazemi, E. (2010). Towards a Holistic Requirement Management Framework for ERP Deployment.
Proceedings of the 2nd International Conference on Engineering Systems Management and Applications, ICESMA 2010, (January), 9398. Retrieved from http://www.aus.edu/conferences/icesma2010/

[20] Rolland, C., \& Prakash, N. (2001). Matching ERP system functionality to customer requirements. Proceedings Fifth IEEE International Symposium on Requirements Engineering, (February 2001), 66-75. https://doi.org/10.1109/ISRE.2001.948545

[21] Shahid N. Bhatti, Maria Usman, Amr A. Jadi, 2015, Validation to the Requirement Elicitation Framework via Metrics. ACM SIGSOFT Software Engineering Notes 40(5): 17, USA. DOI= 2815021.2815031

[22] Shahid N. Bhatti, Aneesa Rida Asghar, Atika Tabassum, "Role of Requirements Elicitation \& Prioritization to Optimize Quality in Scrum Agile Development" International Journal of Advanced Computer Science and Applications (ijacsa), 7(12), 2016. 